\title{
Augmentation of hepatic doxorubicin extraction with extracorporeal filtration avoids the dose-dependent, nonlinear increase in AUC observed with systemic administration
}

Received: 6 February 1997 / Accepted: 9 May 1997

\begin{abstract}
Purpose: Regional therapy of primary or metastatic liver cancer with low hepatic extraction ratio drugs such as doxorubicin is constrained by development of systemic toxicity. To examine the effect of augmentation of hepatic drug extraction, a swine model of hepatic artery infusion (HAI) with minimally invasive hepatic venous isolation and hepatic venous drug extraction (HVDE) was developed to study the comparative pharmacokinetic profiles of regional and systemically administered doxorubicin. Methods: Doxorubicin $0.5-9 \mathrm{mg} / \mathrm{kg}$ was administered to 31 pigs over $90 \mathrm{~min}$ either by HAI with simultaneous HVDE or by standard systemic vein infusion. Systemic artery and hepatic vein plasma samples were collected periodically $(0$ to $240 \mathrm{~min}$ ) for determination of doxorubicin concentrations by high-performance liquid chromatography. Pharmacokinetic profiles were modeled with PCNONLIN 4.2. Results: Concentration-time data were best
\end{abstract}

M.G. Sturgill

College of Pharmacy,

Rutgers, The State University of New Jersey, New Jersey, USA

M.G. Sturgill

Division of Pediatric Pharmacology and Toxicology, University of Medicine and Dentistry of New Jersey-Robert Wood Johnson Medical School, One Robert Wood Johnson Place CN-19, New Brunswick, New Jersey 08903, USA

D.E. Brenner

The Division of Hematology/Oncology, University of Michigan Medical School, Michigan, USA

D.E. Brenner

The Simpson Memorial Research Institute,

102 Observatory Street, Ann Arbor, Michigan 48109, USA

D.A. August

The Division of Surgical Oncology,

University of Medicine and Dentistry of New Jersey-Robert Wood Johnson Medical School, New Brunswick, New Jersey, USA

D.A. August $(\bowtie)$

The Cancer Institute of New Jersey,

195 Little Albany Street, New Brunswick,

New Jersey 08901, USA Tel. (908) 235-7701; Fax (908) 235-7493 described in all pigs by a two-compartment open model of elimination. Independent of the route of administration, AUC and $\mathrm{C}_{\max }$ values increased with dose. Mean systemic AUC and $\mathrm{C}_{\max }$ values were consistently lower with regional administration, with statistically significant decreases at the 0.5 and $3 \mathrm{mg} / \mathrm{kg}$ doses, whereas there was no relationship between hepatic vein parameters and route of administration. There was a linear relationship between mean systemic AUC values and dose in pigs receiving doxorubicin via HAI with HVDE, whereas mean systemic AUC values increased exponentially at doses of $5 \mathrm{mg} / \mathrm{kg}$ or above with systemic vein administration. Conclusions: Administration of doxorubicin by HAI with simultaneous HVDE signifiantly decreases systemic exposure in comparison with standard systemic vein drug infusion, and may protect against nonlinear increases in exposure at higher doses.

Key words Doxorubicin - Pharmacokinetics - Hepatic artery infusion - Hepatic venous drug extraction - Area under the plasma concentration versus time curve $\cdot$ Maximum plasma concentration

\section{Introduction}

Doxorubicin (Fig. 1) is an anthracycline antibiotic with potent tumoricidal activity against a broad spectrum of hematologic and solid tumor types, including lymphocytic and nonlymphocytic leukemias, Hodgkin's and non-Hodgkin's lymphomas, sarcomas, germ cell tumors, mesotheliomas, and carcinomas [34]. The tumoricidal activity of doxorubicin is attributed to several distinct DNA-disruptive processes $[6,9,35,40]$. These processes, many of which are carried out by doxorubicin metabolites generated in the liver, include noncovalent intercalation between 5 '-GC nucleotide base pairs in the DNA helix, classic DNA alkylation reactions, generation of oxygen free radical intermediates, and disruption of DNA repair via inhibition of topoisomerase I and II 


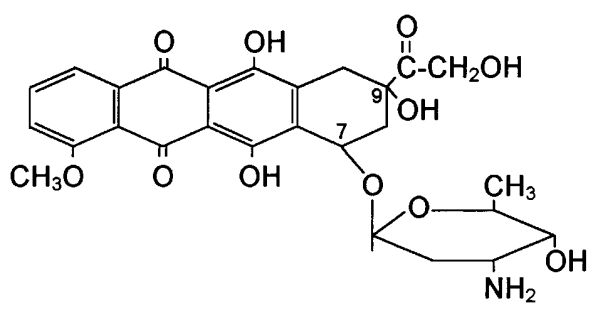

Fig. 1 The chemical structure of doxorubicin. The inactive 4ringed aglycone is a substituted naphthacene quinone which is attached at carbon 7 of ring $\mathrm{D}$ to the amino sugar daunosamine by a glycosidic bond. Modifications of duanosamine alter both toxic and antitumor activity

enzymes $[7,8,17,21,24,29,35,48]$. The utility of doxorubicin does not come without a price. Acute adverse effects include dose-limiting leukopenia, alopecia, radiosensitization, venous flare reactions, and stomatitis $[13,23,34,45]$. An irreversible, cumulative dose-related cardiomyopathy generally limits the use of doxorubicin to a total recommended lifetime dose of $550 \mathrm{mg} / \mathrm{m}^{2}$, even against tumors which are responding to therapy [32].

Regional cancer chemotherapy administration has been investigated with many agents in an attempt to decrease systemic exposure and toxicity [15]. This approach is based on pharmacokinetic principles, with selectivity obtained by increasing the drug concentration at the tumor site while minimizing systemic exposure and toxicity. This selective advantage can be realized if the tumor-bearing organ eliminates a major portion of the chemotherapy dose upon initial exposure (prior to reaching the systemic circulation). Extracorporeal drug removal may be used to augment presystemic drug removal, permitting a selective advantage when using agents not extensively eliminated by the tumor-bearing target tissue $[22,38]$. Regional doxorubicin administration by hepatic artery infusion has been employed for treatment of primary and metastatic liver cancer with disappointing results, even though response rates have been promising [1, 10, 12, 26, 36, 49, 51]. Doxorubicin is extensively metabolized by the liver, with biliary excretion of glucuronide conjugates of 7-deoxydoxorubicin-aglycone or doxorubicinol accounting for about $40 \%$ of overall excretion [6,9]. However, the hepatic extraction ratio of doxorubicin is only $45-50 \%$ [26]. Regional administration without extracorporeal augmentation of drug removal therefore does not significantly reduce systemic exposure or toxicity $[3,14,30]$.

This study investigated the pharmacokinetic profile of doxorubicin administered by hepatic artery infusion (HAI) with simultaneous hepatic venous isolation and hepatic venous drug extraction (HVDE), a method designed to reduce systemic exposure by enhancing presystemic drug removal $[3,18,19,25]$. This method does not require laparotomy. It involves delivery of doxorubicin directly to the liver via the hepatic artery, collection of all hepatic venous effluent, and filtration of drug from effluent prior to systemic reinfusion. Previous re- ports have documented an extraction ratio of 75-91\% with this method of doxorubicin administration, associated with a significant reduction in systemic exposure, as measured by area under the plasma concentration versus time curve (AUC), and a decrease in cardiac tissue concentrations of doxorubicin and doxorubicinol $[3-5,27]$.

\section{Material and methods}

Hepatic venous isolation with hepatic venous drug extraction

A group of 31 female domestic swine (Hodgin's Kennels, Howel, Mich.) weighing $20-37 \mathrm{~kg}$ were studied. All procedures were performed in the morning following a 12-h overnight fast. As previously described, hepatic venous isolation was accomplished using a four-lumen double-balloon polyethylene catheter (Fig. 2) [3-5]. After fluoroscopically guided passage of the catheter into the inferior vena cava, the caudal balloon was inflated superior to the renal veins and the cephalad balloon in the suprahepatic vena cava just below the right atrium. Blood was then withdrawn through intra-balloon catheter fenestrations into the main catheter lumen and out to an extracorporeal circuit. This setup allowed collection of all hepatic venous effluent. The fourth catheter lumen bypassed the main lumen and permitted blood flow from the inferior vena cava below the caudal balloon through the catheter into the suprahepatic vena cava.

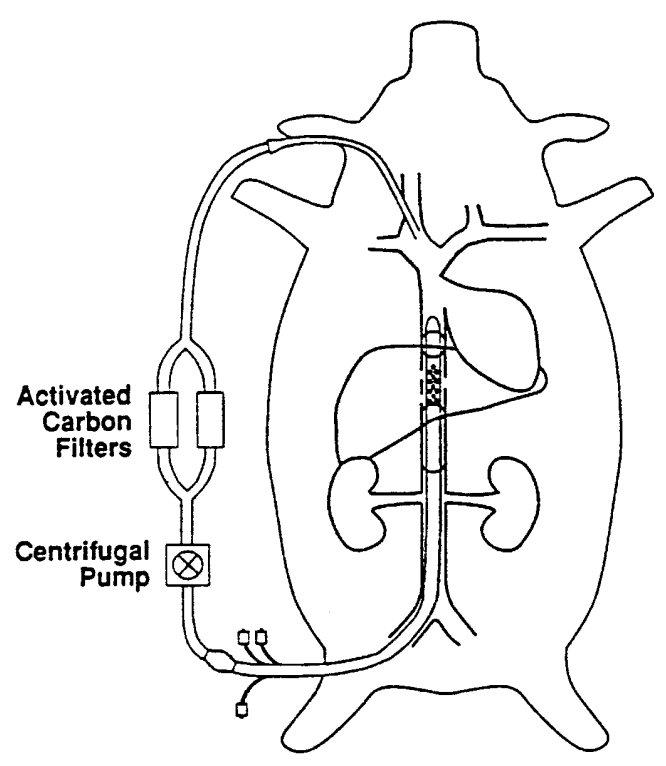

Fig. 2 Schematic representation of the perfusion circuit used to accomplish simultaneous hepatic venous isolation and hepatic venous drug extraction. Hepatic venous effluent was collected by a double-balloon catheter placed within the inferior vena cava. Blood was circulated through the extracorporeal circuit by a centrifugal capacitance pump. Blood flow in the extracorporeal circuit (equal to hepatic blood flow) was measured with an in-line flow transducer. In pigs that received doxorubicin by hepatic artery infusion the effluent was pumped through a pair of parallel, activated-carbon hemoperfusion filters and returned to the pig through a catheter placed within the internal jugular vein. The hemoperfusion filters were removed from the extracorporeal circuit in pigs that received peripheral infusions of doxorubicin (used with permission; [3]) 
HVDE in the extracorporeal circuit was accomplished with two parallel activated-charcoal hemoperfusion filters. HVDE was used in pigs receiving doxorubicin by HAI. The extracorporeal filters were bypassed in pigs receiving doxorubicin by systemic infusion (SYSI), leaving systemic distribution of drug undisturbed. Blood from the circuit was returned to the pig through a 12 French internal jugular central venous catheter.

Hepatic venous isolation in pigs receiving doxorubicin via HAI was achieved by inflation of the caudal and cephalad balloons prior to initiation of the drug infusion. Blood flow through the extracorporeal circuit was maintained with a centrifugal pump, with the rate continuously monitored and adjusted to pump all hepatic venous effluent while preventing development of negative pressure sufficient to collapse the isolated segment of inferior vena cava or hepatic veins.

All animals were sacrificed by lethal injection of Beuthanasia-D (Schering-Plough Animal Health, Kenilworth, N.J.) at completion of each study. At the time of sacrifice, postmortem examination was performed to ensure that the hepatic artery and double-balloon catheters were properly positioned and that no drug extravasation had occurred.

This study was approved by the Subcommittee on Animal Studies of the Ann Arbor Veterans Administration Medical Center.

\section{Doxorubicin administration}

Doxorubicin was administered to 14 swine by HAI and to 17 swine by SYSI via the internal jugular vein at doses of $0.5,1,3,5$, or $9 \mathrm{mg} / \mathrm{kg}$ infused over $90 \mathrm{~min}$. Hepatic venous isolation was performed for 240 min following initiation of HAI or SYSI. In animals receiving doxorubicin via SYSI the hemoperfusion filters were omitted from the extracorporeal circuit.

In all experiments, hepatic venous blood samples (from the extracorporeal circuit prior to filtration) and systemic artery blood samples (from the internal carotid artery) were collected periodically for determination of doxorubicin and metabolite concentrations. In swine receiving doxorubicin by $\mathrm{HAI} / \mathrm{HVDE}$, blood samples were also collected from the extracorporeal circuit before and after filtration to allow determination of efficiency of drug filtration. Samples were obtained at time 0 , at 1, 5, 10, 15, 30, 60, and 90 min after initiation of drug infusion, and (after completion of drug infusion) at 91, 95, 100, 105, 120, 150, and 180 min after initiation of the infusion.

\section{Determination of plasma doxorubicin concentrations}

Plasma doxorubicin concentrations were determined by highpressure liquid chromatography (HPLC) according to the method of Brenner et al. [11]. Briefly, HPLC grade tetrahydrofuran and certified grade ammonium formate, chloroform, and ammonium sulfate were obtained from Fisher Laboratories of Allied Industries (Pittsburgh, Pa.). A doxorubicinol standard was synthesized according to the method of Takanashi and Bachur [46]. Specimens were analyzed following chloroform/isopropanol (1:1 v/v) extraction, with the method modified by the use of a $15-\mathrm{cm} \mu$ Bondapak phenyl column (Waters Associates, Millipore, Milford, Mass.) and a Shimadzu fluorescence flow spectrophotometer. The excitation frequency was $470 \mathrm{~nm}$, with emission measured at $550 \mathrm{~nm}$, permitting a lower limit of detection of doxorubicin in methanol of $0.0005 \mathrm{n} M$, and $1 \mathrm{ml}$ of pooled human plasma of $0.005 \mathrm{n} M$. The purity of doxorubicin and doxorubicinol standards was confirmed by a single HPLC peak at published retention times [11]. At least $95 \%$ purity was suggested by the lack of other peaks in the HPLC trace at the sensitivity used.

\section{Pharmacokinetic analysis}

The pharmacokinetic parameters area under the plasma concentration versus time curve (AUC), apparent volume of distribution at steady state $\left(V_{\mathrm{ss}}\right)$, distribution half-life $\left(\mathrm{t}_{1 / 2 \alpha}\right)$, terminal elimination half-life $\left(t_{1 / 2 \beta}\right)$, and total body clearance $\left(\mathrm{CL}_{\mathrm{T}}\right)$ were estimated from plasma concentration versus time data utilizing nonlinear least squares regression with PCNONLIN 4.2 (SCI Software, Apex, N.C.). The weighted factor in all calculations was the inverse of the square of each plasma concentration. The AUC from time zero to the last measured concentration (180 $\mathrm{min}$ ) was calculated by the linear trapezoidal rule, with extrapolation to time infinity obtained by adding this value to the last measurable concentration divided by $\beta$ (the elimination rate constant obtained from the terminal disposition slope of the plasma concentration versus time curve).

Owing to the observed variability in plasma concentrations during the 90-min infusion period an average "plateau" maximum plasma concentration $\left(\mathrm{C}_{\max }\right)$ value was calculated for each pig and used for all further analyses. This average plateau value included the observed plasma concentrations which by visual inspection of the plasma concentration-time curves fell on the plateau region of the curve.

$\mathrm{V}_{\mathrm{ss}}$ was calculated from the product $\left[\mathrm{V}_{\mathrm{c}}\left(1+\mathrm{K}_{12} / \mathrm{K}_{21}\right)\right]$, where $\mathrm{V}_{\mathrm{c}}$ represents the volume of distribution of the central compartment, $\mathrm{K}_{12}$ the rate constant describing the movement of doxorubicin from the central compartment to the peripheral compartment, and $\mathrm{K}_{21}$ the rate constant describing the movement of doxorubicin from the peripheral compartment to the central compartment. The $t_{1 / 2 \alpha}$ was calculated from the quotient $(\ln 2 / \alpha)$, with $\alpha$ (the distribution rate constant) calculated from plasma concentration versus time data by the method of residuals. The $t_{1 / 2 \beta}$ was calculated from the quotient (n $2 / \beta)$, and $\mathrm{CL}_{\mathrm{T}}$ from the quotient (dose/AUC).

Unless otherwise indicated, all reported pharmacokinetic parameters are given in the form of mean \pm standard error of the mean (SEM).

\section{Statistical analysis}

Mean pharmacokinetic parameters were compared between HAI and SYSI within each dosage cohort by an unpaired Student's $t$-test, or by a Wilcoxon signed rank's test in the case of parameters which were not normally distributed. Linear regression was used to evaluate the potential relationship between dose and hepatic vein or systemic artery AUC values. A two-tailed $P$-value less than 0.05 was considered statistically significant for all analyses.

\section{Results}

\section{Pharmacokinetic analysis}

Of the 31 pigs, 27 survived until at least 90 min after drug infusion had ended. Four deaths occurred in pigs given doxorubicin by SYSI, two of five pigs at the $5 \mathrm{mg} /$ $\mathrm{kg}$ dose and two of two at the $9 \mathrm{mg} / \mathrm{kg}$ dose. The pharmacokinetic parameters for SYSI administration at the $9 \mathrm{mg} / \mathrm{kg}$ dose reported in Tables 1,2 , and 3 represent a single pig, which survived $110 \mathrm{~min}(20 \mathrm{~min}$ after the drug infusion ended).

Mean AUC and $\mathrm{C}_{\max }$ values during HAI and SYSI of doxorubicin are summarized in Table 1. Other hepatic vein pharmacokinetic parameters are summarized in Table 2, and systemic artery parameters in Table 3. Representative mean hepatic vein and systemic artery plasma concentration versus time curves are shown in Fig. 3. The pharmacokinetic behavior of doxorubicin was best described in all pigs by a two-compartment open model, characterized by rapid distribution to a peripheral compartment (mean $t_{1 / 2 \alpha}$ values ranged from $0.69 \pm 0.01$ to $33.9 \pm 7.47 \mathrm{~min})$ and prolonged elimination from the central (plasma) compartment 
Table 1 AUC and $\mathrm{C}_{\max }$ values (mean $\pm \mathrm{SEM}$ ) of doxorubicin in hepatic vein and systemic artery blood with HAI and SYSI (HAI hepatic artery infusion, $S Y S I$ systemic vein infusion, $A U C_{H E P}$ hepatic vein area under the plasma concentration versus time curve,
$C_{\text {maxHEP }}$ hepatic vein maximum plasma concentration, $A U C_{S Y S}$ systemic artery area under the plasma concentration versus time curve, $C_{\max S Y}$ systemic artery maximum plasma concentration). $* P<0.05$

\begin{tabular}{llllclc}
\hline Dose $(\mathrm{mg} / \mathrm{kg})$ & Route & $n$ & $\mathrm{AUC}_{\mathrm{HEP}}(\mu M \min )$ & $\mathrm{AUC}_{\text {SYS }}(\mu M \min )$ & $\mathrm{C}_{\operatorname{maxHEP}}(\mu M)$ & $\mathrm{C}_{\operatorname{maxSYS}}(\mu M)$ \\
\hline 0.5 & HAI & 3 & $31.4 \pm 2.07$ & $5.79 \pm 2.17$ & $0.28 \pm 0.02$ & $0.05 \pm 0.01$ \\
& SYSI & 3 & $28.8 \pm 3.90$ & $67.0 \pm 18.1^{*}$ & $0.24 \pm 0.04$ & $0.66 \pm 0.18^{*}$ \\
1 & HAI & 2 & $59.0 \pm 5.41$ & $15.2 \pm 10.6$ & $0.60 \pm 0.11$ & $0.17 \pm 0.12$ \\
& SYSI & 3 & $45.3 \pm 13.7$ & $82.7 \pm 61.3$ & $0.41 \pm 0.13$ & $0.79 \pm 0.39$ \\
3 & HAI & 3 & $160 \pm 33.4$ & $35.6 \pm 11.5$ & $1.16 \pm 0.16$ & $0.37 \pm 0.14$ \\
& SYSI & 3 & $267 \pm 174$ & $271 \pm 81.9 *$ & $1.00 \pm 0.20$ & $3.29 \pm 0.77^{*}$ \\
5 & HAI & 3 & $390 \pm 92.7$ & $58.1 \pm 14.7$ & $3.68 \pm 1.25$ & $0.50 \pm 0.08$ \\
& SYSI & 2 & $441 \pm 278$ & $1038 \pm 596$ & $3.27 \pm 1.57$ & $8.42 \pm 3.60$ \\
9 & HAI & 2 & $602 \pm 485$ & $92.6 \pm 4.82$ & $5.64 \pm 5.01$ & $0.89 \pm 0.13$ \\
& SYSI $^{\mathrm{a}}$ & 1 & 955 & 3789 & 10.6 & 42.1 \\
\hline
\end{tabular}

${ }^{a} \mathrm{AUC}$ and $\mathrm{C}_{\max }$ calculated between time 0 and the time of death of the pig at $110 \mathrm{~min}$

Table 2 Pharmacokinetic parameters (mean \pm SEM) of doxorubicin in hepatic vein blood with HAI and SYSI (HAI hepatic artery infusion, $S Y S I$ systemic vein infusion, $t_{l / 2 \alpha}$ distribution half-life, $t_{l / 2 \beta}$ terminal elimination half-life, $V_{s S}$ apparent volume of distribution at steady state, $C L_{T}$ total body clearance). ${ }^{*} P<0.05$

\begin{tabular}{llllcrr}
\hline Dose $(\mathrm{mg} / \mathrm{kg})$ & Route & $n$ & $\mathrm{t}_{1 / 2 \alpha}(\mathrm{min})$ & $\mathrm{t}_{1 / 2 \beta}(\mathrm{min})$ & $\mathrm{V}_{\mathrm{ss}}(\mathrm{ml} / \mathrm{kg})$ & $\mathrm{CL}_{\mathrm{T}}(\mathrm{ml} / \mathrm{min})$ \\
\hline 0.5 & HAI & 3 & $2.80 \pm 0.93$ & $62.9 \pm 3.65$ & $492 \pm 104$ & $10.4 \pm 0.58$ \\
& SYSI & 3 & $2.30 \pm 0.93$ & $63.5 \pm 15.0$ & $780 \pm 250$ & $12.4 \pm 1.42$ \\
1 & HAI & 2 & $33.9 \pm 7.47$ & $2.07 \pm 0.92$ & $354 \pm 301$ & $10.5 \pm 3.07$ \\
& SYSI & 3 & $3.01 \pm 0.21$ & $86.3 \pm 18.9 *$ & $1030 \pm 325$ & $17.3 \pm 4.59$ \\
3 & HAI & 3 & $3.50 \pm 1.15$ & $165 \pm 132$ & $1702 \pm 1439$ & $10.5 \pm 0.96$ \\
& SYSI & 3 & $8.68 \pm 5.40$ & $604 \pm 507$ & $3055 \pm 1271$ & $17.6 \pm 8.83$ \\
5 & HAI & 3 & $2.44 \pm 0.59$ & $68.2 \pm 35.5$ & $601 \pm 461$ & $8.42 \pm 1.51$ \\
& SYSI & 2 & $6.28 \pm 1.50$ & $93.1 \pm 16.9$ & $405 \pm 35.9$ & $10.5 \pm 6.60$ \\
9 & HAI & 2 & $4.80 \pm 0.70$ & $693 \pm 0.06$ & $11637 \pm 10906$ & $22.8 \pm 17.5$ \\
& SYSI & 1 & 0.19 & 7.79 & 37.0 & 4.24 \\
\hline
\end{tabular}

${ }^{\text {a }}$ Pharmacokinetic parameters calculated between time 0 and the time of death of the pig at $110 \mathrm{~min}$

Table 3 Pharmacokinetic parameters (mean \pm SEM) of doxorubicin in systemic artery blood with HAI and SYSI (HAI hepatic artery infusion, $S Y S I$ systemic vein infusion, $t_{1 / 2 \alpha}$ distribution half-life, $t_{1 / 2 \beta}$ terminal elimination half-life, $V_{s s}$ apparent volume of distribution at steady state, $C L_{T}$ total body clearance). $* P<0.05$

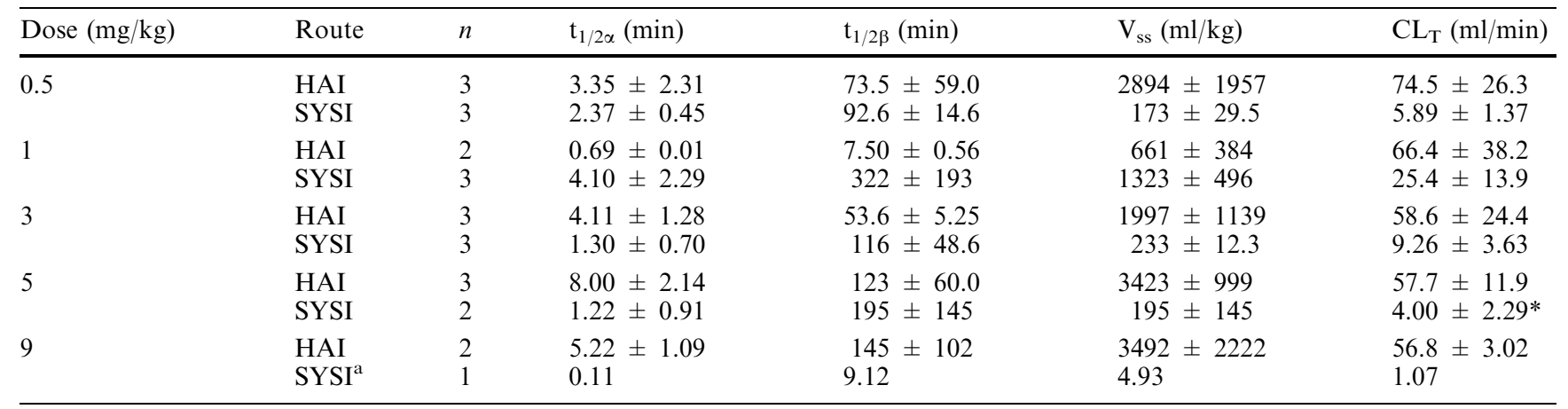

${ }^{a}$ Pharmacokinetic parameters calculated between time 0 and the time of death of the pig at $110 \mathrm{~min}$

(mean $t_{1 / 2 \beta}$ values ranged from $2.07 \pm 0.92$ to $693 \pm 0.06 \mathrm{~min})$.

As shown in Table 1, mean hepatic vein and systemic artery AUC and $\mathrm{C}_{\max }$ values increased in a dose-related fashion with either regional or systemic doxorubicin administration. In contrast, as shown in Tables 2 and 3, there was no dose dependence for any other pharmacokinetic parameter in either hepatic vein or systemic artery blood during HAI or SYSI. $\mathrm{V}_{\mathrm{ss}}$ values were consistently much larger than intravascular volume, with mean values ranging from $173 \pm 29.5$ to $11637 \pm 10906$ $\mathrm{ml} / \mathrm{kg}$, indicating extensive extravascular doxorubicin 
Fig. 3 Mean $( \pm$ SEM) hepatic vein and systemic artery concentrations versus time with hepatic artery (HAI) and systemic vein (SYSI) infusion of doxorubicin $3 \mathrm{mg} / \mathrm{kg}$. (• HAI administration of doxorubicin, $\square$ SYSI administration of doxorubicin)
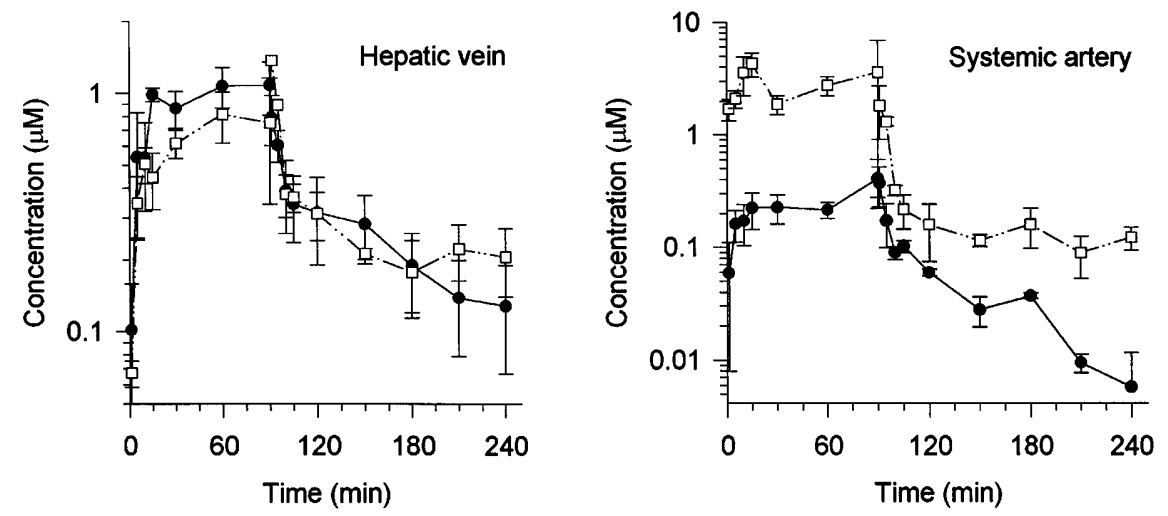

distribution. $\mathrm{CL}_{\mathrm{T}}$ values were consistently higher and $t_{1 / 2 \beta}$ values smaller with HAI/HVDE, but showed no clear relationship to dose.

Hepatic and systemic exposure to doxorubicin

As shown in Table 1 and Fig. 3, HAI/HVDE resulted in lower systemic drug exposure, as measured by mean AUC and $\mathrm{C}_{\max }$ values, than did SYSI of an equal dose. These differences reached statistical significance in the 0.5 and $3 \mathrm{mg} / \mathrm{kg}$ dose cohorts. Accordingly, with $\mathrm{HAI} /$ HVDE hepatic vein AUC $\left(\mathrm{AUC}_{\mathrm{HEP}}\right) /$ systemic AUC $\left(\mathrm{AUC}_{\mathrm{SYS}}\right)$ ratios ranged from 3.88 to 6.71 , and hepatic vein $\mathrm{C}_{\max }\left(\mathrm{C}_{\operatorname{maxHEP}}\right) /$ systemic $\mathrm{C}_{\max }\left(\mathrm{C}_{\operatorname{maxSYS}}\right)$ ratios from 3.43 to 8.33 , although there were no clear relationships between these ratios and dose. In contrast, the $\mathrm{AUC}_{\mathrm{HEP}} / \mathrm{AUC}_{\mathrm{SYS}}$ and $\mathrm{C}_{\operatorname{maxHEP}} / \mathrm{C}_{\operatorname{maxSYS}}$ ratios with SYSI ranged from 0.25 to 0.99 and 0.22 to 0.42 , respectively. Although the differences were not significant, lower systemic exposure was consistently associated with greater $\mathrm{CL}_{\mathrm{T}}$ and shorter $t_{1 / 2 \beta}$ values. As shown in Table 1 and Fig. 3, the reduced systemic exposure to doxorubicin with HAI/HVDE did not result in decreased hepatic exposure. Although there was a trend toward higher $\mathrm{AUC}_{\mathrm{HEP}}$ values with SYSI at higher doses, none of these differences was statistically significant. In contrast, $\mathrm{C}_{\text {maxHEP }}$ values were higher with HAI/HVDE at all but the 5 and $9 \mathrm{mg} / \mathrm{kg}$ doses; again, none of these differences reached statistical significance.

As shown in Fig. 4, AUC $\mathrm{SYS}_{\text {S }}$ values rose linearly with dose when doxorubicin was administered by $\mathrm{HAI} /$ HVDE $(r=0.993 ; P<0.0001)$. In contrast, AUC $\mathrm{SYS}_{\mathrm{S}}$ values increased in an exponential fashion with SYSI $(r=0.999 ; P<0.001)$, indicating disproportionate increases in systemic exposure. The curve began to rise steeply at a dose of approximately $5 \mathrm{mg} / \mathrm{kg}$. Two of five pigs given SYSI of doxorubicin at $5 \mathrm{mg} / \mathrm{kg}$, and both pigs that received $9 \mathrm{mg} / \mathrm{kg}$, died within $90 \mathrm{~min}$ of ending the infusion. Postmortem examination revealed pulmonary edema and hepatic congestion, suggestive of acute doxorubicin toxicity. In contrast, none of the pigs receiving doxorubicin by HAI/HVDE expired prior to completion of pharmacokinetic sampling at $180 \mathrm{~min}$.

\section{Discussion}

At least one-third of all cancer patients develop primary or metastatic liver disease [39, 50]. To overcome the relatively poor response rates of liver tumors to systemic chemotherapy, regional administration of antineoplastic agents has been tried with modest success [20, 28, 31, 37, 42]. Because of its broad spectrum of antitumor activity, there has been particular interest in regional infusion of doxorubicin. Response rates have been promising, but the poor hepatic extraction of this drug limits the utility of this approach since systemic exposure and toxicity remain problematic $[1,2,10,12,26,36,49,51]$. The rationale for HAI/HVDE is to improve the pharmacokinetic profile by removing drug from hepatic venous blood as it leaves the liver, thereby reducing systemic exposure. This study was designed to characterize the pharmacokinetic profile of doxorubicin with this method of administration $[3-5,15,18,19,25]$.
Fig. 4 Correlation between mean $( \pm$ SEM) systemic artery AUC and dose with hepatic artery (HAI) and systemic vein (SYSI) administration of doxorubicin. With HAI administration the correlation is linear, and described by the equation $\mathrm{AUC}(\mu M$ min) $=10.735^{*}$ dose $(\mathrm{mg} / \mathrm{kg}) ; r=0.993$; $P<0.0001$. The relationship between AUC and dose is exponential with SYSI administration above $5 \mathrm{mg} / \mathrm{kg}$, described by the equation $\mathrm{AUC}(\mu M \mathrm{~min})=-278.5+$ $\left[278.5^{*} \mathrm{e}^{\left[0.298^{*} \text { dose }(\mathrm{mg} / \mathrm{kg})\right.}\right] ; r=0.999$; $P<0.001$
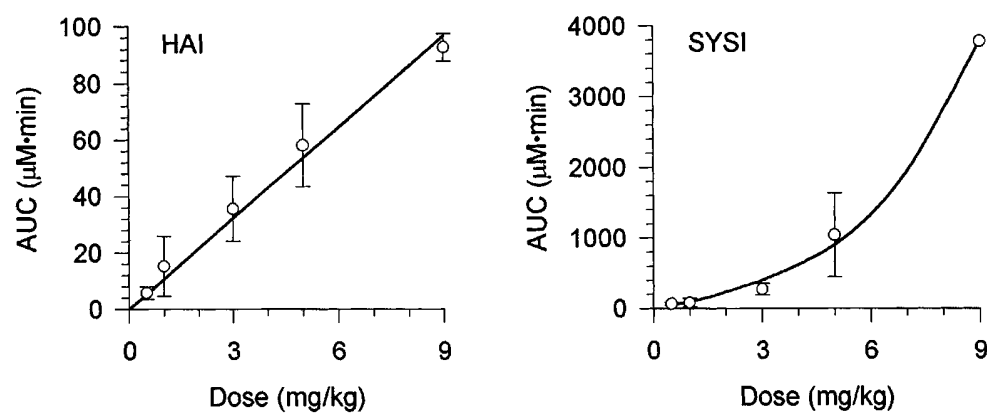
The plasma concentration versus time profiles of doxorubicin observed in this study were best described by a two-compartment open model of elimination, whether drug was administered systemically or regionally. This is in agreement with previous studies, which have reported doxorubicin pharmacokinetics to be independent of route of administration [10,30]. The twocompartment behavior of doxorubicin indicates extensive distribution to an extravascular space (most likely reflecting cellular uptake), followed by prolonged redistribution and elimination from the central (plasma) compartment. The systemic $t_{1 / 2 \alpha}$ and $t_{1 / 2 \beta}$ values observed in our study are in agreement with the results of previous investigators, as are the large $\mathrm{V}_{\mathrm{ss}}$ values $[9,16,33]$. Previous studies suggest that doxorubicin distributes to tissues in relation to nuclear DNA content, with extensive uptake by the liver, kidneys, heart, lymph nodes, skeletal muscle, fat, and skin $[35,47,52]$. Doxorubicin may be sequestered in fatty tissue, as indicated by a previous study reporting decreased clearance in obese cancer patients [43]. The two-compartment behavior observed with both methods of drug administration in this study is therefore not surprising. Independent of route of administration, cellular uptake and DNA intercalation of doxorubicin, which occurs during the initial distribution phase, is reversible. Redistribution to the plasma compartment ultimately permits liver uptake and biliary excretion. Therefore rapid distribution and prolonged elimination would be expected with HAI/HVDE [34].

Systemic exposure to doxorubicin, as measured by mean $\mathrm{AUC}_{\mathrm{SYS}}$ and $\mathrm{C}_{\text {maxSYS }}$ values, was consistently lower with HAI/HVDE in comparison to SYSI (Table 1). These differences reached statistical significance at the 0.5 and $3 \mathrm{mg} / \mathrm{kg}$ doses. In contrast, there were no significant differences in mean $A_{U C H}$ or $\mathrm{C}_{\text {maxHEP }}$ values, suggesting that decreased systemic exposure was not accompanied by a concomitant decrease in hepatic exposure (Table 1). Therefore, HAI/HVDE indeed appears to improve the hepatic pharmacokinetic profile of doxorubicin administration in comparison with standard SYSI $[4,10,30,44]$. This pharmacokinetic advantage with HAI/HVDE, which we have previously reported, was illustrated by the $\mathrm{AUC}_{\mathrm{HEP}} / \mathrm{AUC}_{\mathrm{SYS}}$ and $\mathrm{C}_{\text {maxHEP }} / \mathrm{C}_{\text {maxsys }}$ ratios, which consistently suggested a decrease in systemic doxorubicin exposure of approximately fivefold [4].

Mean systemic $\mathrm{CL}_{\mathrm{T}}$ values were consistently higher and $t_{1 / 2 \beta}$ values lower with HAI of doxorubicin, reflecting the supplemental clearance of drug by HVDE. This is not surprising, given the increase in hepatic doxorubicin extraction ratios (from $50-72 \%$ to $75-91 \%$ ) previously reported with this method of doxorubicin administration $[5,27]$. Mean systemic $\mathrm{CL}_{\mathrm{T}}$ was significantly increased with $\mathrm{HAI} / \mathrm{HVDE}$ at the $5 \mathrm{mg} / \mathrm{kg}$ dose, although there were no significant differences in mean systemic $t_{1 / 2 \beta}$ values. The lack of significance at lower doses in part reflects our lack of statistical power, but may also reflect the disproportionate increases in AUC and $\mathrm{C}_{\max }$ values observed with systemic doxorubicin administration at the $5 \mathrm{mg} / \mathrm{kg}$ and $9 \mathrm{mg} / \mathrm{kg}$ doses (Fig. 4). In contrast, mean hepatic vein $\mathrm{CL}_{\mathrm{T}}$ values were slightly lower with regional administration, although none of these differences was significant. Interestingly, the consistent decrease in mean hepatic vein $\mathrm{CL}_{\mathrm{T}}$ values with regional doxorubicin administration did not correlate with longer $t_{1 / 2 \beta}$ values. Mean hepatic vein $t_{1 / 2 \beta}$ values were consistently shorter with HAI/HVDE, reaching statistical significance at the $1 \mathrm{mg} / \mathrm{kg}$ dose. This behavior may reflect the contribution of the extracorporeal filters to drug extraction, with less drug reaching the systemic circulation and reentering the hepatic circulation.

The relationship between mean systemic artery AUC values and doxorubicin does was linear with $\mathrm{HAI} /$ HVDE $(r=0.993, P<0.0001)$. In contrast, the relationship between systemic AUC values and dose with SYSI was exponential $(r=0.999 ; P<0.001)$. While this relationship is based on only a few data points, because of the lethality of high-dose systemic infusions, data obtained from two pigs at the $5 \mathrm{mg} / \mathrm{kg}$ dose and one pig at the $9 \mathrm{mg} / \mathrm{kg}$ dose that died before they were suitable for formal pharmacokinetic analysis confirm disproportionate doxorubicin exposure whether measured by AUC or $\mathrm{C}_{\max }$. Nonlinear increases in systemic exposure to doxorubicin observed in our study could result clinically in severe toxicity, as the normal routes of detoxification and elimination become saturated [41]. The one pig that received $9 \mathrm{mg} / \mathrm{kg}$ by SYSI and survived longer than 90 min after completion of the drug infusion had a systemic AUC at 110 min (just prior to death) of $3889 \mu M$ min, a value which was more than threefold higher than the total AUC of any other pig in this study. In contrast, regional administration of doxorubicin, even at the highest dose of $9 \mathrm{mg} / \mathrm{kg}$, did not result in premature death of any pig in the study. Extracorporeal filtration of doxorubicin therefore appeared not only to augment drug clearance, but to enhance safety as well, indicating both a pharmacokinetic and pharmacodynamic improvement in doxorubicin disposition. This method of administration may permit regional doxorubicin therapy for primary or metastatic hepatic tumors with higher doses designed to exploit the therapeutic dose-response relationship of the drug while preventing increased systemic toxicity.

In summary, we have demonstrated that the pharmacokinetic profile of doxorubicin administered by HAI/HVDE or SYSI is best characterized by a twocompartment model, indicating widespread extravascular distribution of drug with either route of administration. Regional administration resulted in significant reductions in systemic exposure as measured by systemic artery AUC and $\mathrm{C}_{\max }$ values. In addition, there is evidence that augmentation of drug extraction with extracorporeal filtration avoids the dose-dependent nonlinear increase in AUC observed with SYSI. HAI/HVDE may permit safe and effective use of doxorubicin, a drug normally hampered by low hepatic extraction, for regional therapy of primary or metastatic hepatic tumors. 


\section{References}

1. Arai Y, Sone Y, Inaba Y, Ariyoshi Y, Kido C (1994) Hepatic arterial infusion chemotherapy for liver metastases from breast cancer. Cancer Chemother Pharmacol [Suppl] 33: S142

2. August DA (1996) Theoretic and experimental aspects of regional liver infusion. Surg Oncol Clin NAm 5: 399

3. August DA, Verma N, Andrews JC, Vaerten MA, Brenner DE (1994) Hepatic artery infusion of doxorubicin with hepatic venous drug extraction. J Surg Res 56: 611

4. August DA, Verma N, Vaerten MA, Shah R, Andrews JC, Brenner DE (1995) Pharmacokinetic evaluation of percutaneous hepatic venous isolation for administration of regional chemotherapy. Surg Oncol 4: 205

5. August DA, Verma N, Vaerten MA, Shah R, Brenner DE (1995) An evaluation of hepatic extraction and clearance of doxorubicin. Br J Cancer 72: 65

6. Bachur NR (1975) Adriamycin (NSC-123127) pharmacology. Cancer Chemother Rep [Part 3] 6: 153

7. Bagchi D, Bagchi M, Hassoun EA, Stohs SJ (1995) Adriamycin-induced hepatic and myocardial lipid peroxidation and DNA damage, and enhanced excretion of urinary lipid metabolites in rats. Toxicology 95: 1

8. Bartoszek A, Wolf CR (1992) Enhancement of doxorubicin toxicity following activation by NADPH cytochrome P450 reductase. Biochem Pharmacol 43: 1449

9. Benjamin RS, Riggs CE Jr, Bachur NR (1977) Plasma pharmacokinetics of adriamycin and its metabolites in humans with normal hepatic and renal function. Cancer Res 37: 1416

10. Bern MM, McDermott W, Cady B, Oberfield RA, Trey C, Clouse ME, Tullis JL, Parker LM (1978) Intraarterial hepatic infusion and intravenous adriamycin for treatment of hepatocellular carcinoma. Cancer 42: 399

11. Brenner DE, Galloway S, Noone R, Hande KR (1985) Improved high performance liquid chromatography assay of doxorubicin. Comparison to thin layer chromatography. Cancer Chemother Pharmacol 13: 139

12. Carr BI, Iwatsuki S, Starzl TE, Selby R, Madariaga J (1993) Regional cancer chemotherapy for advanced stage hepatocellular carcinoma. J Surg Oncol 3S: 100

13. Chabner BA, Myers CE, Oliverio VT (1977) Clinical pharmacology of anticancer drugs. Semin Oncol 4: 165

14. Chen HSG, Gross JF (1980) Intra-arterial infusion of anticancer drugs: theoretic aspects of drug delivery and review of responses. Cancer Treat Rep 64: 31

15. Collins JM (1984) Pharmacologic rationale for regional drug delivery. J Clin Oncol 2: 498

16. Creasey WA, McIntosh LS, Brescia T, Odujinrin O, Aspnes GT, Murray E, Marsh JC (1976) Clinical effects and pharmacokinetics of different dosage schedules of adriamycin. Cancer Res 36: 216

17. Cummings J, Willmott N, Hoey BM, Marley ES, Smyth JF (1992) The consequences of doxorubicin quinone reduction in vivo in tumour tissue. Biochem Pharmacol 44: 2165

18. Curley SA, Byrd DR, Newman RA, Ellis HJ, Chase J, Carrasco CH, Cleary K, Bodden W, Hohn DC (1993) Reduction of systemic drug exposure after hepatic arterial infusion of doxorubicin with complete hepatic venous isolation and extracorporeal chemofiltration. Surgery 114: 579

19. Curley SA, Stone DL, Fuhrman GM, Hohn DC, Siddik ZH, Newman RA (1993) Increased doxorubicin levels in hepatic tumors with reduced systemic drug exposure achieved with complete hepatic venous isolation and extracorporeal chemofiltration. Cancer Chemother Pharmacol 33: 251

20. Curley SA, Newman RA, Dougherty TB, Fuhrman GM, Stone DL, Mikolajek JA, Guercio S, Guercio A, Carrasco $\mathrm{CH}$, Kuo MT (1994) Complete hepatic venous isolation and extracorporeal chemofiltration as treatment for human hepatocellular carcinoma: a phase I study. Ann Surg Oncol 1: 389
21. Cutts SM, Parsons PG, Sturm RA, Phillips DR (1996) Adriamycin-induced DNA adducts inhibit the DNA interactions of transcription factors and RNA polymerase. J Biol Chem 271: 5422

22. Dedrick RL, Oldfield EH, Collins JM (1984) Arterial drug infusion with extracorporeal removal. I. Theoretic basis with particular reference to the brain. Cancer Treat Rep 68: 373

23. Donaldson SS, Glick JM, Wilbur JR (1974) Adriamycin activating a recall phenomenon after radiation therapy. Ann Intern Med 81: 407

24. Foglesong PD, Reckord C, Swink S (1992) Doxorubicin inhibits human DNA topoisomerase I. Cancer Chemother Pharmacol 30: 123

25. Fuhrman GM, Cromeens DM, Newman RA, Cleary KR, Carrasco CH, Wright KC, Guercio S, Guercio A, Curley SA (1994) Hepatic arterial infusion of verapamil and doxorubicin with complete hepatic venous isolation and extracorporeal chemofiltration: pharmacological evaluation of reduction in systemic drug exposure and assessment of hepatic toxicity. Surg Oncol 3: 17

26. Garnick MB, Ensminger WD, Israel MA (1979) A clinical pharmacological evaluation of hepatic arterial infusion of adriamycin. Cancer Res 39: 4105

27. Ku Y, Samizo M, Fukumoto T, Shiki H, Maekawa Y, Iwasaki T, Tominaga M, Kuroda Y, Saitoh Y (1993) Comparison of hepatic tissue extraction rates of cytotoxic anticancer drugs during hepatic arterial chemotherapy-evaluation using direct hemoperfusion under hepatic venous isolation. Jpn J Gastroenterol 90: 41

28. Ku Y, Tominaga M, Iwasaki T, Kitagawa T, Maeda I, Shiotani M, Kusunoki S, Maekawa Y, Samizo M, Fukumoto T, Kuroda Y, Hirota S, Saitoh Y (1996) Percutaneous hepatic venous isolation and extracorporeal charcoal hemoperfusion for high-dose intraarterial chemotherapy in patients with colorectal hepatic metastases. Surg Today 26: 305

29. Kukielka E, Cederbaum AI (1990) NADPH- and NADHdependent oxygen radical generation by rat liver nuclei in the presence of redox cycling agents and iron. Arch Biochem Biophys 283: 326

30. Lee YTN, Chan KK, Harris PA, Jordan LC (1980) Distribution of adriamycin in cancer patients: tissue uptakes, plasma concentration after IV and hepatic IA administration. Cancer 45: 2231

31. Lotze MT, Flickinger JC, Carr B (1993) Hepatobiliary neoplasms. In: DeVita VT, Hellman S, Rosenberg SA (eds) Cancer: principles and practice of oncology. JB Lippincott, Philadelphia, p 883

32. Minow RA, Benjamin RS, Gottlieb JA (1975) Adriamycin (NSC-123127) cardiomyopathy-an overview with determination of risk factors. Cancer Chemother Rep [Part 3] 6: 195

33. Mross K, Maessen P, Vijgh WJF van der, Gall H, Boven E, Pinedo HM (1988) Pharmacokinetics and metabolism of epidoxorubicin and doxorubicin in humans. J Clin Oncol 6: 517

34. Myers CE (1987) Anthracyclines. In: Pinedo HM, Longo DL, Chabner BH (eds) Cancer chemotherapy and biologic response modifiers. (Annual 9) Elsevier, Amsterdam, p 36

35. Myers CE Jr, Chabner BA (1990) Anthracyclines. In: Chabner AC, Collins JM (eds) Cancer chemotherapy, principles and practice. Lippincott, Philadelphia, p 6

36. Nakashima K, Aramaki M, Kawano K, Yoshida T, Kim YI, Kitano S, Kobayashi M (1995) Postoperative adjuvant arterial infusion chemotherapy in patients with advanced hepatocellular carcinoma. Jpn J Cancer Chemother 22: 1483

37. Niederhuber JE, Ensminger WD (1993) Treatment of metastatic cancer to the liver. In: DeVita VT, Hellman S, Rosenberg SA (eds) Cancer: principles and practice of oncology. JB Lippincott, Philadelphia, p 2201

38. Oldfield EH, Clark WC, Dedrick RL, Egorin MJ, Austin HA, DeVroom HD, Joyce KM, Doppman JL (1987) Reduced systemic drug exposure by combining intraarterial cis-diamminedichloroplatinum(II) with hemodialysis of regional venous drainage. Cancer Res 47: 1962 
39. Pickren JW, Tsukada Y, Lane WW (1982) Liver metastases: analysis of autopsy data. In: Weiss L, Gilbert MA (eds) Liver metastasis. GK Hall, Boston, p 2

40. Powis G (1987) Metabolism and reactions of quinoid anticancer agents. Pharmacol Ther 35: 57

41. Preiss R, Sohr R, Kittelmann B, Muller E, Haase D (1989) Investigations on the dose-dependent pharmacokinetics of adriamycin and its metabolites. Int $\mathbf{J}$ Clin Pharmacol Ther Toxicol 27: 156

42. Ravikumar TS, Pizzorno G, Bodden W, Marsh J, Strair R, Pollack J, Hendler R, Hanna J, D'Andrea E (1994). Percutaneous venous isolation and high-dose hepatic arterial infusion chemotherapy for unresectable liver tumors. J Clin Oncol 12: 2723

43. Rodvold KA, Rushing DA, Tewksbury DA (1988) Doxorubicin clearance in the obese. J Clin Oncol 6: 1321

44. Shiotani M, Ku Y, Kusunoki N, Kitagawa T, Maeda I, Tominaga M, Tanigawara Y, Kuroda Y, Saitoh Y (1995) Pharmacokinetic comparison of intraarterial and intraportal infusion of adriamycin in regional chemotherapy of the liver. Jpn J Cancer Chemother 22: 1560

45. Souhami L, Feld R (1978) Urticaria following intravenous doxorubicin administration. JAMA 240: 1624
46. Takanashi S, Bachur NR (1976) Adriamycin metabolism in man. Evidence from urinary metabolites. Drug Metab Dispos 4: 79

47. Terasaki T, Iga T, Sugiyama Y, Hanano M (1982) Experimental evidence of characteristic tissue distribution of adriamycin. Tissue DNA concentration as a determinant. J Pharm Pharmacol 34: 597

48. Tewey KM, Rowe TC, Yang L, Halligan BD, Liu LF (1984) Adriamycin-induced DNA damage mediated by mammalian DNA topoisomerase II. Science 226: 466

49. Urist MM, Balch CM (1990) Intra-arterial chemotherapy for hepatoma using adriamycin administered via an implantable constant infusion pump (abstract). Proc Am Assoc Cancer Res 24: 148

50. Willis RA (1973) The spread of tumors in the human body. Butterworth, London, pp 19, 175

51. Yasui M, Nonami T, Kurokawa T, Nakao A, Harada A, Hashimoto S, Kajikawa M, Hiraoka E, Takagi H (1994) Effects of hepatic arterial infusion chemotherapy on unresectable or recurrent hepatocellular carcinoma. Cancer Chemother Pharmacol [Suppl] 33: S139

52. Yesair DW, Schwartzbach E, Shuck D, Denine EP, Asbell MA (1972) Comparative pharmacokinetics of daunomycin and adriamycin in several animal species. Cancer Res 32: 1177 